\title{
The Impact of an Ethical Environment on Managers' Project Evaluation Judgments under Agency Problem Conditions
}

By

\author{
Peter Booth $\mathrm{a}^{\mathrm{a}^{*}}$ \\ and \\ Axel K-D. Schulz \\ ${ }^{\mathrm{a}}$ Chancellery, University of Technology, Sydney, Australia \\ ${ }^{\mathrm{b}}$ Department of Accounting, University of Melbourne, Australia
}

\begin{abstract}
*All Correspondence to:
Professor Peter Booth

Fax: 61-2-9514-1351

Peter.Booth@uts.edu.au
\end{abstract}

AOS accepted version, matched to published text 2004, Vol. 29, Nos 5-6, pp 473-488 


\title{
The Impact of an Ethical Environment on Managers' Project Evaluation Judgments under Agency Problem Conditions
}

\begin{abstract}
This paper proposes that a strong ethical environment will be effective in reducing the tendency for managers to continue failing projects in both the presence and absence of agency problems. The findings support these propositions, with a strong ethical environment found to significantly reduce managers' tendency to continue failing projects. Also, while agency problem effects were still present under a strong ethical environment, their impact was similar to the case of a weak ethical environment in the absence of agency problems. These findings suggest that creating a strong ethical environment may be a highly desirable control option for organizations generally.
\end{abstract}

Key Words:

Escalation of commitment, ethics, agency theory, project evaluation, management control systems. 


\section{The Impact of an Ethical Environment on Managers’ Project Evaluation Judgments under Agency Problem Conditions}

\section{Introduction}

A large body of research has been conducted which examines decision bias in project evaluation decisions (for example, Staw 1976; Staw and Fox, 1977; Northcraft and Wolf, 1984; Chenhall and Morris, 1991). The general tendency that emerges from this body of work is that under certain conditions managers are biased towards continuing failing projects; the escalation of commitment phenomenon (Brockner, 1992). One stream of this research supports the agency theory view that agency problems ${ }^{1}$ are an important set of conditions under which escalation of commitment to failing projects arises (Harrison and Harrell, 1993; Harrell and Harrison, 1994). Agency theory posits that an agency problem exists when managers' economic interests differ from those of their firm (for example, a potential job promotion dependent on management of only successful projects) and they possess relevant information not available to their superiors (for example, private knowledge of a failing project which should be discontinued) (Baiman, 1982, 1990; Eisenhardt, 1989). Under such conditions managers have both an incentive to act against the interests of the firm and the opportunity to do so without their superiors detecting their self-interested action. Under these conditions, the work of Harrell and Harrison suggests that managers will act in their own selfinterest to continue projects that are failing. Passmore (1995) and Rutledge and Karim (1999) have confirmed this finding in similar experimental studies.

While these findings are consistent with the expanded view of rational decision-making incorporated into agency theory, ${ }^{2}$ recently Rutledge and Karim (1999) proposed that this decision-making model was incomplete as it ignored the influence of managers' ethical reasoning on their economic decisions. Drawing upon Noreen's (1988) critique of the boundaries of the applicability of the pure agency model, they argued that not all managers 
are motivated by self-interest but may be constrained by their own ethical sensibility or conscience, and that this may explain why in Harrell and Harrison's work some subjects who experienced agency problem conditions still acted in the interests of their firm. In short, if acting in one's own interest against the interests of the firm is perceived as being unethical, then managers may moderate the tendency to continue failing projects. ${ }^{3}$ In a behavioral decision-making experiment, Rutledge and Karim (1999) found that the strongest tendency for managers to continue failing projects was where an agency problem existed and managers had relatively lower levels of ethical reasoning. However, where no agency problem existed or managers had relatively higher levels of ethical reasoning, then the tendency was for managers to make decisions consistent with the interests of the firm.

Rutledge and Karim (1999) demonstrate that an improved model of managers’ decisionmaking behaviour can be gained by including ethical considerations through variations in managers' level of ethical reasoning. However, a manager's level of ethical reasoning is only one source of the potential interaction of ethical considerations with agency problem conditions. Consistent with Noreen's (1988) arguments that ethical behavior by managers might be more common than opportunistic behavior, it has been suggested that the “...ability to see and respond ethically may be related more to attributes of corporate culture than to attributes of individual employees” (Chen, Sawyer and Williams, 1997, p. 856, quoted in ICAC, 1998, p.10). Similarly, it has been argued that organizations can foster an 'epidemic of ethical behaviour' (Arnold, Lampe and Sutton, 1999, 2000) and act as 'moral agents' where ethical decisions involve more than individual values and standards (Metzger and Dalton, 1996). Where the mission and values, leadership and management influence, peer group influence, procedures, rules and codes of ethics, ethics training, and rewards and sanctions of an organization are all directed to supporting ethical decision-making, they mutually reinforce each other to create a strong ethical environment that promotes greater levels of ethical decision making by all managers (Ford and Richardson, 1994). 
A strong ethical environment provides a specific context within which an organization operates and all managers make decisions, and thereby can be considered as distinct from ethical reasoning, which is an internal characteristic of a manager. Therefore, regardless of their level of ethical reasoning, a strong ethical environment may lead to a general tendency for managers to act in the interests of their organizations and, more specifically, a reduced tendency for managers to act opportunistically under agency problem conditions. This proposition is consistent with the arguments by Arnold et al. $(1999,2000)$ that an organization can create an ethical culture that becomes contagious and ultimately leads to a more ethical organization.

The purpose of this study is to provide another perspective on how an improved model of managers' decision-making behavior can be derived. It does this by considering how one important component of the organizational context of decision-making, the strength of the ethical environment, influences managers' economic decisions. Such a perspective is important as it moves beyond the individual traits (self-interest, ethical reasoning) focus in prior research to explicitly consider how the context within which managers' make decisions impacts on their judgments. ${ }^{4}$ We propose that a strong ethical environment reduces project managers' tendency to continue a failing project both in the absence and presence of agency problems. However, the impact of a strong ethical environment is expected to be stronger in the latter case than the former. Thus, we also propose an interaction effect between the form of ethical environment and agency problem conditions. These propositions are explored in a behavioral decision-making experiment and support is found for the proposed role of strong ethical environments in reducing escalation of commitment to failing projects.

The remainder of this paper is divided into four sections. The first section develops hypotheses based upon the prior research on agency theory and arguments on how an ethical environment may impact upon managers’ economic decisions both generally and specifically in the case of agency problems. The second section overviews the research design, dependent 
and independent variables and the third presents the results of the experiment. The final section discusses the results, presents conclusions derived from the study and provides suggestions for future research.

\section{Hypothesis Development}

\section{Agency theory and managers’ project evaluation decisions}

Consistent with Conlon and Leatherwood's (1989) proposal to consider approaches that provide rational economic explanations rather than just irrational affective ones for managers' tendency to continue failing projects, a number of experimental and analytic studies have considered agency theory explanations for managers' normatively incorrect project evaluation decisions (Kanodia, Bushman and Dickhaut, 1989; Harrison and Harrell, 1993; Harrell and Harrison, 1994; Passmore, 1995; Rutledge and Karim, 1999). Agency theory models the relationships between principals (for instance, a firm's senior management) and agents (for instance, project managers) in terms of contracts to perform certain duties. It posits that an agent will act in her/his own interests, and that where these interests are not aligned with those of the principal, the 'incentive’ element of an agency problem exists (Baiman, 1982, 1990; Eisenhardt, 1989). However, the agent only has the opportunity to exploit this incentive if a state of information asymmetry (that is, where the principal does not possess information available to the agent which is needed to monitor the agent's actions) provides an opportunity for the agent to act in his/her self-interest without detection by the principal. When both an incentive and opportunity to act in their self-interest exist, than agency theory proposes that an agency problem exists, and agents are expected to make decisions that are aligned with their self-interests rather than with the interests of the principal (Baiman, 1982, 1990; Eisenhardt, 1989).

Under agency problem conditions agency theory proposes that it would be economically rational for managers to continue projects that are failing. For example, if a project manager's 
reward, promotion or career prospects were dependent on managing only successful projects and his/her superiors did not possess sufficient information to evaluate project profitability independently, then it may be in the project manager's economic interests to continue a failing project even though this is against the profit maximizing interests of the organization. Harrison and Harrell (1993), Harrell and Harrison (1994), Passmore (1995) and Rutledge and Karim (1999) provide experimental evidence that consistently supports the agency theory explanation for such bias in managers' project evaluation decisions. These studies found that there is a lower tendency for managers to terminate a failing project when the agency problem conditions of an incentive for managers to act in their self-interest and information asymmetry are present. These findings provide the problem domain for this study.

\section{The impact of ethics on agency problem induced bias in managers' project evaluation decisions}

The problem domain of this study is examined in the context of Noreen's (1988) arguments that in practice the standard agency problem outcome of self-interested decisions might be a special case; that is, that ethical behavior may be more common than opportunistic behavior. He proposed that more research should consider the situations under which standard agency outcomes do not hold even though the necessary theoretical conditions are present. One such boundary condition is variation in the ethical attributes of managers. Within the context of managers' normatively incorrect project evaluation decisions, Rutledge and Karim (1999) provide support for Noreen’s arguments in terms of how differences in manager's moral reasoning abilities interact with agency problems. This study considers another boundary condition, variation in the ethical environments of organizations.

\section{Ethics as an attribute of managers}

Rutledge and Karim (1999) contrast agency theory’s assumption that an individual's actions are based upon extreme and immediate self-interest and a selfish character with a counter assumption that individuals may have an altruistic or unselfish belief system. They argued that such a belief system might exist for managers with a high level of ethical 
reasoning. Citing prior research findings (Ponemon, 1992, 1993; Tsui and Gul, 1996) of a direct positive relationship between higher levels of ethical and moral reasoning and more ethical actions, Rutledge and Karim (1999) suggested that managers with high ethical and moral reasoning may act in an ethically correct way rather than an agency theory opportunistic way. Using these two potentially conflicting views about individual preferences and beliefs, Rutledge and Karim (1999) proposed that project managers' with a low level of ethical and moral reasoning would be more likely to act in their own self-interest than project managers' with a high level of ethical reasoning, and that this difference in decision behavior would be greater where agency problem conditions exist.

Rutledge and Karim (1999) conducted a decision-making experiment based on the Harrell and Harrison (1994) study using a 2 x 2 factorial design. One independent variable was the absence or presence of agency problem conditions (both misaligned interests and private information) and the second was the ethical reasoning level (higher or lower) of subjects. They found a significant interaction between agency problem conditions and project managers' ethical reasoning level. The project evaluation decisions of managers with a high ethical reasoning level were not significantly influenced by the presence of agency problem conditions. However, managers with a low ethical reasoning level had a greater tendency to continue a failing project under agency problem conditions than in their absence. This supported their argument that agency theory explanations for decision bias should not be substantial for managers with a high level of ethical reasoning (Rutledge and Karim, 1999, p.176).

\section{Ethics as an attribute of organizations}

The level of ethical reasoning of managers is only one element of the ethical context of economic decision-making that might limit agency problems (Noreen, 1988). It has been suggested by others that the “...ability to see and respond ethically may be related more to attributes of corporate culture than to attributes of individual employees” (Chen, Sawyer and 
Williams, 1997, p. 856, quoted in ICAC, 1998, p.10). Similarly, Arnold et al. (1999, 2000) argue for creating ethically driven organizations that foster an epidemic of ethical behaviour, Metzger and Dalton (1996) conceptualize organizations as 'moral agents' where ethical decisions involve more than individual values and standards, and the New South Wales Independent Commission Against Corruption (ICAC) ${ }^{5}$ argues that the organization is a “...very powerful influence which has the potential to make an ethical person act unethically or an ethical person behave ethically” (ICAC, 2000, p. 1).

These arguments suggest that attributes of an organization's internal environment can directly impact upon decisions made by managers separately from individual managers’ levels of ethical and moral reasoning. Consistent with these views, it is proposed in this paper that the general ethical environment within an organization, and in its industry, may promote a climate of ethical decision-making, which in turn may mitigate agency problem induced tendencies for managers to continue failing projects.

ICAC (1998), drawing on Ford and Richardson (1994), identifies eight factors that influence the ethical environment of an organization, six of which are relevant to the arguments above; mission and values, leadership and management influence, peer group influence, procedures, rules and codes of ethics, ethics training, and rewards and sanctions. ${ }^{6}$ The potential impact of each these factors on ethical behavior in an organization is summarized in Table 1.

\section{[Insert Table 1 about here]}

The first three factors (mission and values, leadership and management influence and peer group influence) reflect the important role that social norms, particularly moral ones, may play in creating a general social environment in which people are exposed to social pressure not to act opportunistically (Noreen, 1988). Such arguments are consistent with the well-documented powerful effects of social and organizational norms on the actions of social actors (for example, Beyer, 1981; Brunsson, 1982; Gowler and Legge, 1983). For example, 
institutional theory provides numerous examples of how normative isomorphism exerts pressure for decision-makers and their organizations to conform to the expectations of interorganizational networks of professional groups (Zucker, 1983, 1987). Therefore, such literature provides broad general support for the expectations summarized in Table 1 that where a strong environment of organizational norms supports ethical decision-making, this creates significant social pressures to conform that reduce the motivation for managers to act in their self-interest where these are not aligned with the interests of the organization. In addition, further social pressure is brought upon individual members to act consistently with the ethical culture of the organization if other managers publicly act consistently with that culture and senior management is seen to support this behavior (Arnold et. al., 1999).

The fourth and fifth factors (procedures, rules and codes of ethics, and ethics training) reflect the role that social practices have in reinforcing social norms. Norms of ethical behavior may be reinforced within an organization by the creation and deployment of various procedures and policies aimed at both encouraging and requiring ethical decision-making on a wide range of organizational activities. The creation of such ethical procedures and policies has become more common and highly visible in many commercial organizations since the (so-called) excesses of the 1980s (Louwers, Ponemon and Radtke, 1997). The most explicit example of such procedures and policies are Codes of Ethics, which are increasingly imposed by commercial organizations (Farrell and Farrell, 1997; Wiley, 1995). The existence of such organizational practices explicitly supporting ethical decision-making provides regular, concrete reinforcement of ethical norms of behavior.

Finally, the sixth factor (rewards and sanctions) emphasizes the well know finding that alignment of organizational reward systems with desired goals and behaviors is critical for the successful achievement of these goals and behaviors (for example, Merchant, 1989). Therefore, if an organization puts in place all the other above five factors that act to create an ethical environment, then it is also important that it both rewards ethical behavior through 
either explicit public promotion of adherence to its ethical standards and/or by explicit recognition in its promotion and compensation systems, and also has clear public sanctions for breaches of its ethical standards.

Therefore, it is argued that the existence of organizational and social norms that support ethical behavior, their reinforcement through visible adherence to ethical attitudes and behavior by other managers and through explicit ethically based procedures and policies, and linkages to reward systems can create a strong ethical environment within an organization (see Arnold et al., 1999, 2000; Ford and Richardson, 1994; ICAC, 1998, 2000; Metzger and Dalton, 1996). As Arnold et al. (1999) argue, the distinguishing feature of organizations in the final fourth stage of their transitional model of ethical organizational development is their “...consistent application of an ethical orientation to decision making throughout the organization, at all levels of employees, and over an extensive period of time” (1998, p.12). Arnold et al. (1999) present examples of organizations that they argue exemplify such total integration of ethical behavior; Ben and Jerry’s Ice Cream (Miller, 1995; Wiesendanger, 1993) and Johnson \& Johnson (Greenwald, 1986; Johnson, 1989). In combination, the above arguments suggest that a strong ethical environment will create a general tendency for managers to more strongly align their behavior with the norms of the organization, resulting in greater levels of ethical decision making by all managers within the organization. This should lead to project managers making project evaluation decisions that are more consistent with the interests of the organization than where the ethical environment is weaker, regardless of any individual manager's personal level of ethical reasoning.

To examine the above propositions we propose a main effect for a strong ethical environment in our behavioral decision-making experiment. Accordingly, the first hypothesis of this study is:

H1. Project managers who are subject to a strong ethical environment will exhibit a greater tendency to terminate a failing project than project managers who are subject to a weak ethical environment. 
The main effect for a strong ethical environment is likely to act in a counter direction to the agency problem main effect established in the prior literature (specifically, Harrison and Harrell, 1993; Harrell and Harrison, 1994; Rutledge and Karim, 1999), as Rutledge and Karim (1999) found for project managers with a high level of ethical reasoning. That is, we expect that a strong ethical environment will act to constrain project managers' agency problem motivated decision-making behavior. This leads us to propose an interaction effect between the strength of the ethical environment and the presence of agency problems.

In addition to the arguments presented for H1, two sets of arguments suggest further ways in which a strong ethical environment may specifically reduce managers' self-interest incentives where an agency problem exists. The first set of arguments is drawn from the similarity between our view on the role of an ethical environment and professional pronouncements on the critical role of management integrity and ethical environments as part of an effective internal control environment to reduce financial fraud (SAS No. 78 and No. 82; COSO, 1992). Several studies of internal control where accountants had a motivation and opportunity to engage in fraudulent reporting provide support for these pronouncements. While Rich, Smith and Mihalek (1990) and Brief, Dukerich, Brown and Brett (1996) found no support for codes of conduct acting in isolation to influence how individuals resolved ethical dilemmas, they did conclude that ethical environments were important in such cases. D'Aquila (1998) conducted an experiment with members of the AICPA that tested the individual and combined effects of 1) senior management support for ethical decisions, 2) implementation of codes of conduct, and 3) actions that did not create pressure or link compensation to achieving short-term performance targets, on the propensity to fairly report financial information. She found that in combination these three control environment factors increased the propensity to fairly report, and that senior management support was the only individual factor that did so. While these studies do not directly address project managers' project evaluation judgments, they lend support to the argument that a strong ethical 
environment will reduce the tendency for managers to act in their self-interest under agency problem conditions.

The second set of arguments is drawn from agency theory, which proposes that the tendency to act opportunistically will be reduced under agency problem conditions where agents believe that there is either a high probability of punishment if detected and/or the punishment is likely to be severe (Baiman, 1982, 1990). It is proposed that where a strong ethical environment exists agents will assign a higher probability to both the likelihood and severity of punishment if they are detected acting opportunistically. ${ }^{7}$ Thus, even when the probability of detection is low due to the presence of information asymmetry, project managers' higher punishment assessments under a strong as opposed to weak ethical environment will reduce the motivation to act in their self-interest.

Overall, therefore, when agency problem conditions are present, project managers who experience a weak ethical environment will have no countervailing influences to their selfinterest and will act to satisfy these by continuing failing projects. In contrast, those who experience a strong ethical environment will be exposed to a range of countervailing influences that send a strong signal of the need to act ethically, and thus will not act on their self-interest. However, when agency problem conditions are absent, a strong ethical environment will have less impact. While the main effect arguments for an ethical environment suggest that all managers will make more ethical decisions under a strong ethical environment, in the absence of agency problems conditions there are no clear incentives for managers operating under a weak ethical environment to act against the interests of their organization by continuing a failing project. Therefore, we would expect the impact of a strong ethical environment might vary across different agency problem conditions. Accordingly, the second hypothesis of this study is:

H2 The increased likelihood of project managers' tendencies to terminate failing projects for project mangers who are subject to a strong ethical environment will be greater 
where agency problem conditions are present (i.e. both an incentive and opportunity for mangers to act in their self-interest exist) then when they are absent.

\section{Research method}

\section{Overview of design}

Based upon the decision-making case used by Harrell and Harrison (1994), a laboratory experiment was conducted to investigate hypotheses 1 and 2. A 2x2 fully crossed factorial experimental design was used, with agency problem (present/absent) and ethical environment (strong/weak) as the independent variables. The dependent variable was subjects' preference for dis/continuing a project. The subjects, procedures and variables are described in the following subsections.

\section{Subjects}

A total of 131 subjects took part in the experiment. The subjects were middle managers who were completing a part-time MBA at a major university. There were 77 (61\%) males and 49 (39\%) females ${ }^{8}$ and their average age was 32 years (range 23 to 48$) .{ }^{9}$ The subjects had, on average, 10 years of work experience (range 1 to 28 years), with $74 \%$ having 5 or more years of experience. ${ }^{10}$ This experience covered a range of general management and functional occupations in both services and manufacturing activities, with the main areas being general management (16\%), financial roles (13\%), engineering (13\%), sales (7.6\%) and marketing (5.3\%). As mature subjects with significant real world business and management experience, they were considered appropriate for the decision-making task used in this experiment.

As the subjects were volunteers they were offered incentives to both take part in the experiment and to increase their motivation to complete the task. They were told that on completion of the experiment their name would be entered in a draw for a prize of a book voucher. There were three levels of prizes for each experimental session - the first prize had a value of $\$ 48$, the second $\$ 32$ and third prize $\$ 16$. Overall, subjects had a 1-in-10 chance of wining a prize. To take part in the prize draw, subjects entered their name and contact details 
on a sheet separate to the experimental instruments. They handed the sheet to the experimenter at the conclusion of the session, independently of their anonymously completed instruments. A random draw was conducted after the completion of the session, the winners announced and the prizes were mailed in the week after the experiment was held.

\section{Procedures}

All subjects completed an experimental task adapted from that used by Harrell and Harrison (1994), who had designed the task to address the major criticisms of prior experimental tasks used in the literature (Conlon and Leatherwood, 1989). The task instructed subjects to assume the role of a project manager who had four years ago initiated a project with an estimated seven-year life. When initiated, the seven-year cash flow projections for the project were profitable ( $\$ 270,000$ per year on a $\$ 1,000,000$ investment), and the actual cash flows for the first four years had exceeded projections (\$320,000 per year). However, the projections for the remaining three years indicate a sharp decline (to $\$ 50,000$ per year) that will make the project unprofitable. The net present value of the remaining life of the project was indicated to be $\$ 144,327$, while its salvage value if discontinued after four years was indicated to be $\$ 177,500$. The decision for the project manager at this time was whether to continue or discontinue the project. The normatively correct decision was to terminate the project.

Each subject was randomly assigned to one of four cases. The first version of the case contained the basic project information indicated above, and the 'absent' agency problem and 'weak' ethical environment conditions. The second and third versions of the case contained the basic information plus manipulations of either the agency problem or ethical environment conditions. The fourth version contained the basic information plus manipulations of both conditions.

All subjects were given a package consisting of an instruction sheet, their case version and debriefing questionnaire consisting of manipulation check and demographic questions. 
The experimenter led the subjects through the instructions and then instructed them to turn to the decision case. When they had completed the decision case they were instructed to complete the debriefing questionnaire. Subjects took on average between 15 and 20 minutes to complete the experiment.

\section{Dependent variable}

The subjects reached their continuance or discontinuance decisions on a 10-point scale that has been used in similar prior experiments (Harrison and Harrell, 1993; Harrell and Harrison, 1994; Passmore, 1995; Ho and Vera-Muñoz, 1998; Rutledge and Karim, 1999). The scale was divided at its mid-point (between 5 and 6) and labeled so that a choice of 1 to 5 indicated a continuance decision and a choice of 6 to 10 indicated a discontinuance decision. The end points were anchored for 'definitely' continue or discontinue. Thus, the larger the numerical response indicated by a subject the greater the tendency to terminate the project (with scores of 5 or less against the normatively correct decision and scores of 6 or more in accord with the normatively correct decision).

\section{Independent variables}

The two independent variables were agency problem (present/absent) and ethical environment (strong/weak). The agency problem manipulation mirrored that used by Harrell and Harrison (1994) and Rutledge and Karim (1999). In the 'absent' agency problem condition the project manager was cast as a senior project manager with a solid industry reputation for project management gained over a number of years. A single failed project would not damage this well-established reputation. In addition, it was stated that information about the project's unprofitable future performance was widely known to others in the firm and industry, indicating that the manager had no information asymmetry advantage. Thus, there was no incentive or opportunity to act against the interests of the firm. The 'present' agency problem condition manipulated both the incentive and opportunity to act in the manager's self-interest. The manager was cast as a junior project manager with a growing 
reputation for completing profitable projects. The manager had recently received an informal job offer with another company for a promotion and substantial salary increase, but this offer would be withdrawn if the manager had a failed project. It was also stated that the project's expected decline in performance was known only to the project manager and would not become known by others until the projects completion in three years time (For details see the Appendix in Rutledge and Karim, 1999).

The ethical environment condition was developed for this study. In the 'weak' condition subjects were told no explicit information about the ethical environment within the firm. In the 'strong' ethical environment condition subjects were told about conditions existing in the firm and industry that aligned with the factors ${ }^{11}$ described in Table 1 that influence the ethical environment of an organization. Mission and Values: that their company operated in an industry where high ethical standards were valued and that their company actively supported the industry association stance on ethical behavior. Leadership and Management Influence: that managers in their company had always practiced in an environment where trustworthiness, respect, justice, fairness and honesty were of paramount importance and that their superior held them personally responsible for adherence to the industry Code of Ethics. Peer Group Influence: that based upon personal observation of other managers, they believed that there was a high level of adherence to the industry Code of Ethics within the company and the industry. Procedures, Rules and Codes of Ethics: that the industry association had a Code of Ethics that formalized the industry's long-standing expectations for high ethical standards and that their company had adopted the industry code of ethics as its own internal code. Rewards and Sanctions: that the industry association operated an Ethical Practice Review Board that investigated breaches of the Code of Ethics, recommended sanctions to senior management in member companies and published its investigations in the association's widely read monthly magazine, and that their company explicitly valued ethical behavior in its reward and evaluation systems. 
As well as mirroring the factors in Table 1, the elements of a strong ethical environment mirror many of the elements of highly ethical organizations discussed in Arnold et al. (1999), and are consistent with the elements of an effective internal control environment discussed by D’Aquila (1998). Finally, the manipulations focus solely on aspects of an ethical environment that are independent of an implicit or explicit imputation of the manager's own level of ethical reasoning. These manipulations were developed and refined in pilot tests involving two prior experiments using undergraduate business students as subjects. In the pilot testing they were found to induce the desired decision-making behavior. The full strong ethical environment manipulation is shown in the Appendix.

\section{Manipulation checks}

Two manipulation checks were conducted in relation to subjects' perceptions of agency problem conditions and one manipulation check was conducted into subjects' perceptions of the ethical environment. The agency problem condition questions asked whether the information about the project was common knowledge and whether another company had initiated confidential discussion about recruiting them to a more important position with a substantially higher salary. The ethical environment question asked whether ethical behavior by managers was valued in their company and a Code of Ethics was in place to formalise such expectations. Of the 51 subject that failed manipulation checks, 23 (17.5\%) subjects failed one or both of the agency problem manipulation checks, 13 (9.9\%) failed the ethical environment manipulation check and 15 (11.4\%) failed all three manipulation checks.

Due to the high failure rate, the analysis reported in the next section was repeated using only the 80 subjects who responded correctly to all the manipulation check questions. As the

results from the analysis with the reduced data set did not differ significantly ${ }^{12}$ from the analysis using the complete set of subjects, only the latter is reported in this paper. 


\section{Data analysis and results}

\section{Statistical tests}

An overall 2x2 analysis of variance (ANOVA) test was conducted. This test was used to establish whether there was a significant difference between the agency problem treatment groups, the ethical environment treatment groups (H1) and to test for any interaction between agency problem and ethical environment (H2) treatments. All analyses were conducted using SYSTAT $10^{13}$ at an alpha level of 0.05 .

\section{Descriptive statistics}

Descriptive statistics for the four treatments are reported in Table 2. Some general trends are apparent from these descriptive statistics. On average, subjects who experienced agency problem conditions expressed a relatively lower tendency (5.338) to terminate a failing project than subjects who did not experience agency problem conditions (6.561). Similarly, subjects who were subject to a weak ethical environment expressed a relatively lower tendency (5.277) to terminate a failing project than subjects who were subject to a strong ethical environment (6.621). Further, the difference in tendency to terminate projects where agency problems were present (1.364) is fairly similar to the difference in tendency to terminate projects were agency problems were absent (1.270). Finally, only subjects who experienced agency problems in a weak ethical environment made, on average, a project continuation decision (score of 5 or less), which was against the normatively correct decision.

\section{[Insert Table 2 about here]}

\section{Hypotheses testing}

The ANOVA, reported in Table 3, shows a significant agency problem main effect $\left(F_{1,127}=5.249, p=0.024\right)$. The mean response given by project managers (refer Table 2$)$ who experienced agency conditions (5.338) is significantly lower than the mean response given by project mangers who did not experience an agency problem (6.561). This indicates that the former managers were less likely to terminate the failing project than the latter. This finding, 
as expected, is consistent with the prior finding of Harrison and Harrell (1993), Harrell and Harrison (1994), Passmore (1995) and Rutledge and Karim (1999).

\section{[Insert Table 3 about here]}

Hypothesis 1 predicted that project managers who are subject to a strong ethical environment would exhibit a greater tendency to terminate a failing project than project managers who are subject to a weak ethical environment. As indicated in Tables 2 and 3, the mean response given by project managers who experienced a strong ethical environment (6.621) is significantly higher $\left(\mathrm{F}_{1,127}=6.407, \mathrm{p}=0.013\right)$ than the mean response provided by subjects who experienced a weak ethical environment (5.277), which shows that the former managers were more likely to terminate the failing project than the latter. This provides support for hypothesis 1 .

Finally, hypothesis 2 predicted that the difference in the tendency to terminate a failing project between a strong and weak ethical environment would be greater where project mangers experience agency problem conditions than where they did not experience them. The results for the interaction between agency and ethical environment (refer Table 3) show that the difference in tendency to terminate a failing project between strong and weak ethical environments is not significantly different between managers experiencing agency problems and those not experiencing agency problems $\left(\mathrm{F}_{1,127}=0.008, \mathrm{p}=0.928\right)$. Hence, hypothesis 2 is not supported.

\section{[Insert Figure 1 about here]}

Based on the analysis of the two main effects and the interaction, it is concluded that the significant main effect for agency problem supports the finding of prior studies that agency problems reduce managers' tendencies to terminate unprofitable projects; that is, agency problem conditions induce escalation of commitment. In terms of controlling such behavior, the significant main effect for ethical environment supports the proposition that a strong ethical environment increases managers' tendencies to terminate such projects in general; that 
is, to make the normatively correct decision whether agency problem conditions are present or not. Further, while there was no significant interaction, only subjects who experienced agency problems in a weak ethical environment made, on average, the normatively incorrect decision to continue the project. Also, on average, the decisions of subjects who experienced a weak ethical environment and no agency problems are very similar to those who experienced a strong ethical environment and agency problems, as illustrated in Figure 1. Taken together these results provide some indication that a strong ethical environment may provide some counter to the effect of agency problems.

\section{Discussion and conclusions}

Agency theory proposes that under conditions of an agency problem, it is economically rational for managers to continue with projects that are failing. However, as Noreen (1988) argued, under agency problem conditions in practice not all managers display opportunistic behavior. Such arguments suggest that the expanded view of rational decision-making incorporated in agency theory is incomplete. Rutledge and Karim (1999) recently provided evidence that managers' high ethical predisposition may reduce managers' tendency to act in their self-interest; thereby providing one set of conditions under which managers may make rational decisions that do not display opportunistic behavior. This paper set out to examine another potential set of such conditions, the general ethical environment in which managers make decisions.

Research questions were developed and tested in a behavioral decision-making experiment. The presence and absence of agency problem conditions was manipulated along with the elements of an ethical environment. It was anticipated that the presence of a strong ethical environment would induce managers to act in the normatively correct manner by deciding to terminate the project regardless of the presence or absence of agency problem conditions. Further, it was expected that where agency problem conditions induced managers 
to act opportunistically by deciding to continue a failing project a strong ethical environment would mitigate such a tendency. In combination, it was expected that the greatest tendency for managers to act opportunistically would be under agency problem conditions combined with a weak ethical environment and that the opposite set of conditions would result in the greatest tendency for managers to make the normatively correct decision.

The statistically significant difference between the mean responses of project managers experiencing agency problem conditions versus those that did not confirmed previous findings by Harrison and Harrell (1993), Harrell and Harrison (1994) and Rutledge and Karim (1999) that the presence of agency problem conditions induces managers to make project evaluation decisions which are in their self-interest, but against the interests of their organization. However, the statistically significant difference between the mean responses of project managers experiencing a strong ethical environment versus those that did not (hypothesis 1) indicated that the presence of a strong ethical environment increases the tendency for project managers to make decisions aligned with the interests of their organization under both the presence and absence of agency problem conditions. The strongest impact of a strong ethical environment was found where there are no agency problem conditions, but a strong ethical environment also reduces the impact of agency problems when they are present. While no significant interaction was found between agency problem and ethical environment conditions (hypothesis 2), it is of note that project managers who experienced a weak ethical environment and no agency problem conditions made similar project termination decisions to managers who experienced a strong ethical environment and agency problems conditions.

The most important implication of these findings is that the creation of a strong ethical environment represents a viable control design alternative for an organization attempting to provide a general decision environment that aligns managers' interests with those of the organization. The findings indicate that by focusing on creating an environment where the 
organization's mission and values are built upon strong ethical values, where the leadership of the organization acts in ways to explicitly support such mission and values, as do all members of the organization, where these values as given existence in a Code of Ethics and in other relevant organizational procedures and rules, and where organizational rewards and sanctions are explicitly aligned to support ethical values and behavior, then the organization can promote greater levels of ethical decision making by all managers (Ford and Richardson, 1994; ICAC, 1998, 2000). The findings also lend support to the arguments of Chen, Sawyer and Williams (1997) that acting ethically may be related more to corporate culture than to the attributes of employees and of Arnold et al. (1999, 2000) that an organization can create an ethical culture that becomes contagious and ultimately leads to a more ethical organization.

Further, the findings suggest that a strong ethical environment mitigates to some extent project managers’ pursuit of opportunistic behavior. Traditional control alternatives to such agency problems have included considerations of alignment of monetary reward systems with the interest of the firm, and the introduction of more elaborate accounting systems to monitor the agent's decisions. A more recently identified alternative is the selection of managers with a high ethical predisposition (Rutledge and Karim, 1999). The findings in this paper suggest that organizations that believe there may be agency problems with their managers should consider creating a strong ethical environment as an alternative to directly removing agency problem conditions, which is often not a practical alternative.

A second implication of the findings in this study is the provision of further insights into the generalizability of agency theory in the domain of accounting-based economic decisions. Rutledge and Karim (1999) provided evidence that “....agency models of self-interest based managerial decision-making are incomplete and need to be refined to include other potential influences” (p. 181) by showing that managerial self-interest was not acted upon where managers had a personal high ethical predisposition. This study has provided some evidence that aspects of the decision context in which managers make economic decisions based upon 
accounting information, specifically the strength of the ethical environment in the organization, may also mitigate the role of self-interest. Therefore, we propose that further examination of the relationship of the agency theory assumption that behavior can be explained solely by a focus on self-interest with the conditions of a strong ethical environment is warranted.

The findings presented in this paper have to be interpreted within the context of the strengths and limitations of this study. A laboratory study was used to examine the effect of ethical environments and agency problem conditions, because it provides a high degree of internal validity. The research instrument was based on an existing instrument developed by Harrell and Harrison (1994), which provided further validity to this study. However, as with most laboratory studies of this type, the case situations are simplified abstractions of the real world, and care needs to be taken to generalize from this abstraction. Further, as this is the first study examining ethical environments within organizations as a behavioral control option, further refinements are possible to the case descriptions relating to the ethical environment.

Future research could build on this study by attempting to refine the elements of a strong ethical environment included in this study. For example, future research could consider the relative importance of linking ethical behavior to rewards and evaluation systems versus the manager's belief that there is a high level of adherence (i.e. socialized effect) to ethical environment in the organization. In addition, future research could explore the impacts of how the elements of a strong ethical environment are combined and/or identify other potential elements. Along with the refinements to the ethical environment variable, a further extension would be to examine how managers' ethical predisposition (Rutledge and Karim, 1999) interacts with a strong ethical environment. As Rutledge and Karim found ethical predisposition to be a strong moderator to agency problem conditions, it would be interesting to see if it is as important in organizations providing strong ethical environments. If ethical 
predispositions lose their importance in the context of strong ethical environments then this will have direct consequences to hiring and training policies in organizations. Another desirable extension could investigate whether participation in the formulation of the organization's ethical policy has effects on subsequent decisions by project managers. This study has only examined the context where subjects had no explicit role in the development of the ethical code. It would be interesting to determine whether the effectiveness of environmental context is more or less effective where subjects have the environmental context imposed on them versus being part of its development.

\section{Acknowledgements}

We would like to acknowledge Adrian Harrell for providing copies of his research instruments, the pilot work for this project undertaken by David Passmore as his thesis for Bachelor of Business (Honours) at the University of Technology, Sydney, and David Brown for research assistance on this project. We would also like to thank Peter Luckett, David Smith, Cynthia Jeffrey, Steve Salterio, Chris Ittner, participants at the 1998 AAANZ and ABO conferences and the two anonymous referees for their helpful comments on this research. The data and instruments on which this paper is based may be obtained from the authors upon request. 


\section{Appendix. Strong ethical environment case scenario}

Williams Company operates in an industry where high ethical standards are valued. The Industry Association has for several years had a Code of Ethics that formalised the industry's long-standing expectations for high ethical standards in managers. The Industry Association has an Ethical Practice Review Board that investigates any breaches of this code and recommends sanctions to senior management in member companies. Outcomes of such investigations are reported in the Industry Association's monthly magazine, which is read widely in the industry. Managers in the Williams Company have always practiced in a company environment where trustworthiness, respect, justice, fairness and honesty are of paramount importance. Williams Company actively and strongly supports the Industry Association stance on ethical behaviour and has adopted the Industry Association Code of Ethics as its own internal code. To further encourage adherence to the Code of Ethics, Williams Company explicitly values ethical behaviour in its reward and evaluation systems. As part of these systems, your superior holds you personally responsible for adherence to the Code of Ethics. Based upon personal observation of the behaviour of other managers within your company and in others in the industry, you believe there is a high level of adherence to the Code of Ethics both within Williams company and within the industry generally. 
Table 1 Factors that influence the ethical environment of an organization

\begin{tabular}{|c|c|c|}
\hline Factors & Impacts on Ethical Behavior & Key References \\
\hline $\begin{array}{l}\text { Mission and } \\
\text { values }\end{array}$ & $\begin{array}{l}\text { A clear mission and values help create the shared sets of } \\
\text { beliefs that guide decision-making. Where these are } \\
\text { built around strong ethical values they can reinforce } \\
\text { ethical decision-making norms. In addition, ethical } \\
\text { decisions are increased where managers strongly } \\
\text { identify with the organization. }\end{array}$ & $\begin{array}{l}\text { Ping, } 1996 \\
\text { Kitson \& Campbell, } 1996 \\
\text { Akaah, } 1992 \\
\text { Ford \& Richardson, } 1994\end{array}$ \\
\hline $\begin{array}{l}\text { Leadership and } \\
\text { management } \\
\text { influence }\end{array}$ & $\begin{array}{l}\text { Staff are more likely to follow what they see their } \\
\text { superiors do than adhere to an ethics policy. In } \\
\text { particular, explicit formal or informal CEO support for } \\
\text { ethical behavior results in more ethical decisions. } \\
\text { Equally, observation of senior managers acting contrary } \\
\text { to ethical expectations undermines the ethical } \\
\text { development of an organization. }\end{array}$ & $\begin{array}{l}\text { Andrews, } 1989 \\
\text { Soutar, McNeil \& Molster, } 1994 \\
\text { Hegarty \& Sims, } 1979 \\
\text { Cooke \& Zipparo, } 1998 \\
\text { Ford \& Richardson, } 1994\end{array}$ \\
\hline $\begin{array}{l}\text { Peer group } \\
\text { influence }\end{array}$ & $\begin{array}{l}\text { Individuals will adhere to group norms even though this } \\
\text { may be against what they would do as individuals } \\
\text { (groupthink effect). In addition, the 'risky-shift' group } \\
\text { effect, where groups make higher risk decisions than as } \\
\text { individuals, may strengthen the groupthink effect } \\
\text { because in such cases individuals do not see the group } \\
\text { outcome as their responsibility. Thus ethical groups } \\
\text { may induce individuals with low moral reasoning to act } \\
\text { ethically or unethical groups may induce individuals } \\
\text { with high moral reasoning to act unethically. }\end{array}$ & $\begin{array}{l}\text { Nichols \& Day, } 1982 \\
\text { Posner, } 1986 \\
\text { Izraeli, } 1988 \\
\text { Zey-Ferrell, } 1979 \\
\text { Ford \& Richardson, } 1994\end{array}$ \\
\hline $\begin{array}{l}\text { Procedures, rules } \\
\text { and codes of } \\
\text { ethics }\end{array}$ & $\begin{array}{l}\text { The existence of codes of ethics and defined procedures, } \\
\text { rule and roles are perceived as supporting higher ethical } \\
\text { behavior. Existence of codes also increases perceptions } \\
\text { that the organization has a greater concern for ethical } \\
\text { behavior. However, codes must be supported by clear } \\
\text { accompanying sanctions to be effective. }\end{array}$ & $\begin{array}{l}\text { Ferrell \& Skinner, } 1988 \\
\text { Rich, Smith \& Mihalek, } 1990 \\
\text { Laczniak \& Inderrieden, } 1987 \\
\text { Ford \& Richardson, } 1994\end{array}$ \\
\hline Ethics training & $\begin{array}{l}\text { Appropriately focused ethics training, particularly that } \\
\text { with a practical rather than philosophical emphasis, can } \\
\text { assist in encouraging ethical decision-making. Training } \\
\text { can make codes of ethics concrete, but must be seen as } \\
\text { consistent with the other factors. }\end{array}$ & $\begin{array}{l}\text { Brumback, } 1991 \\
\text { Barker, } 1993 \\
\text { Ford \& Richardson, } 1994\end{array}$ \\
\hline $\begin{array}{l}\text { Rewards and } \\
\text { sanctions }\end{array}$ & $\begin{array}{l}\text { Unethical behavior is increased if it is aligned with } \\
\text { organizational rewards and decreased if ethical } \\
\text { decisions are so aligned. Unethical behavior is } \\
\text { decreased where there is a clear threat of punishment. In } \\
\text { particular, punishment having a social, public aspect } \\
\text { will be more effective than private punishment. }\end{array}$ & $\begin{array}{l}\text { Hegarty \& Sims, } 1978 \\
\text { Chonko \& Hunt, } 1985 \\
\text { Ford \& Richardson, } 1994\end{array}$ \\
\hline
\end{tabular}




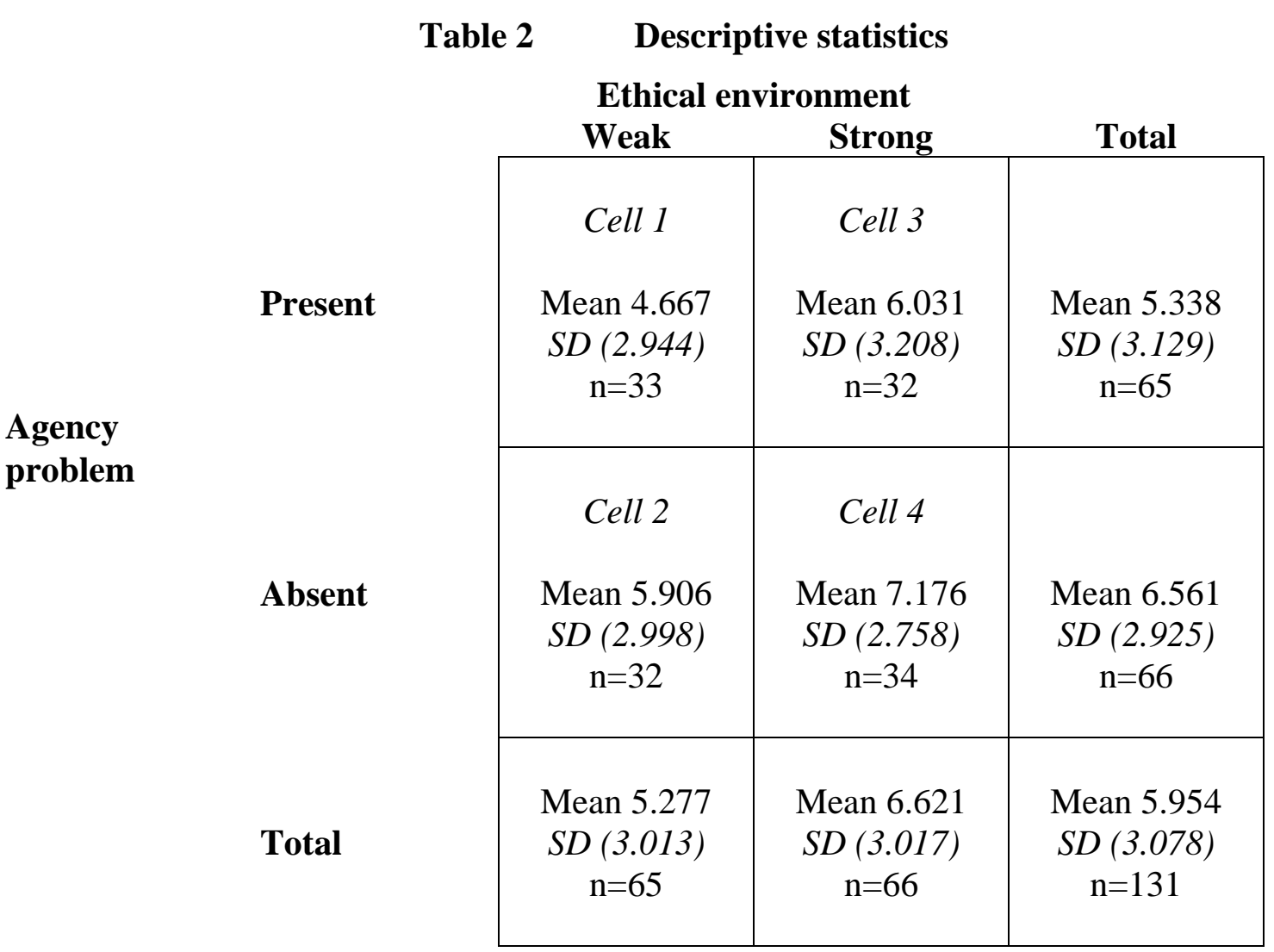

Note: Lower values (5 or less) indicate a decision to continue a project, while higher values (6 or more) indicate a decision to discontinue a project

Table 3 Analysis of variance

\begin{tabular}{|l|c|c|c|c|c|}
\hline \multicolumn{7}{|c|}{ Analysis of variance } \\
\hline \multicolumn{1}{|c|}{ Source } & Sum-of squares & df & Mean-square & F & p (2-tailed) \\
\hline Ethical environment & 56.803 & 1 & 56.803 & 6.407 & 0.013 \\
\hline Agency problem & 46.535 & 1 & 46.535 & 5.249 & 0.024 \\
\hline Eth. Env. x Agency & 0.073 & 1 & 0.073 & 0.008 & 0.928 \\
\hline & & & & & \\
\hline Error & $1,125.962$ & 127 & 8.866 & & \\
\hline
\end{tabular}


Figure 1 Impact of ethical environment

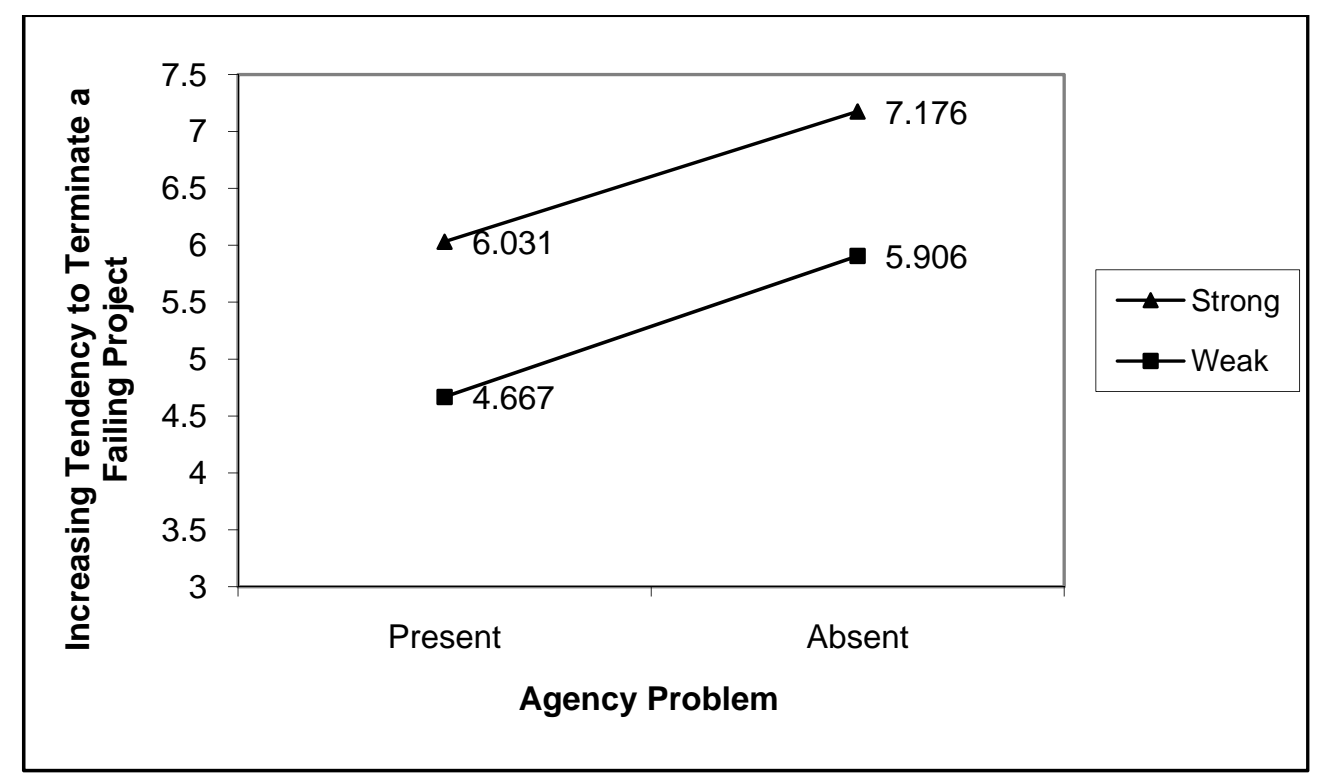




\section{REFERENCES}

Akaah, I. P. (1992). Social inclusion as a marketing ethics correlate. Journal of Business Ethics, 11, 599-608.

American Institute of Certified Public Accountants (AICPA) (1995). Statement of Auditing Standards No. 78: Consideration of Internal Control in a Financial Statement Audit: An Amendment to SAS No. 55. New York: American Institute of Certified Public Accountants.

American Institute of Certified Public Accountants (AICPA) (1997). Statement of Auditing Standards No. 82: Consideration of Fraud in a Financial Statement Audit. New York: American Institute of Certified Public Accountants.

Andrews, K. R. (1989). Ethics in practice. Harvard Business Review, Sept.-Oct, 99-104.

Arnold, V., Lampe, J. C., \& Sutton, S. G. (1999). Understanding the factors underlying ethical organizations: Enabling continuous ethical improvement. Journal of Applied Business Research, 15, 3, 1-20.

Arnold, V., Lampe, J. C., \& Sutton, S. G. (2000). Creating an ethically driven organization: A model for fostering an epidemic of ethical intensity. Advances in Accounting Behavioral Research, 3, 201-224.

Arnold, V., \& Ponemon, L. (1991). Internal auditors' perceptions of whistle-blowing and the influence of moral reasoning: An experiment. Auditing: A Journal of Theory and Practice, pp. 1-15.

Baiman, S. (1982). Agency research in managerial accounting: A survey. Journal of Accounting Literature, 1, 154-213.

Baiman, S. (1990). Agency research in managerial accounting: A second look. Accounting, Organizations and Society, 15, 341-371.

Barker, R. A. (1993). An evaluation of the ethics program at General Dynamic. Journal of Business Ethics, 12, 165-177.

Brockner, J. (1992). The escalation of commitment to a failing course of action: Toward theoretical progress. Academy of Management Review, 17, 39-61.

Beyer, J. (1981). Ideologies, values, and decision making in organizations. In Nystrom, P. \& W. Starbuck, Handbook of Organizational Design, vol. 2. New York: Oxford University Press.

Brief, A. P., Dukerich, J. M., Brown, P. R., \& Brett, J. F. (1996). What's wrong with the Treadway Commission report? Experimental analysis of the effects of personal values and codes of conduct on fraudulent financial reporting. Journal of Business Ethics, 15, 183-198.

Brunsson, N. (1982). The irrationality of action and action rationality: Decisions, ideologies and organizational actions. Journal of Management Studies, 19, 29-44.

Brumback, G. B. (1991). Institutionalizing ethics in government. Public Personnel Management, 20, 353-364.

Chen, A. Y. S., Sawyer, R. B., \& Williams, P. F. (1997). Reinforcing ethical decisions through corporate culture. Journal of Business Ethics, 16, 855-865. 
Chenhall, R., \& Morris, D. (1991). The effect of cognitive style and sponsorship on the treatment of opportunity costs in resource allocation decisions. Accounting, Organizations and Society, 16, 27-46.

Chonko, L. B., \& Hunt, S. D. (1985). Ethics and marketing management: An empirical examination. Journal of Business Ethics, 13, 339-359.

Conlon, E., \& Leatherwood, M. (1989). Sunk costs and financial decision making: Integration and implications. Advances in Financial Planning and Forecasting, 37-61.

Committee of Sponsoring Organizations of the Treadway Commission (COSO) (1992). Internal Control: Integrated Framework: Framework. Harborside, NJ: American Institute of Certified Public Accountants.

Cooke, S., \& Zipparo, L. (1998). Reducing corruption: Views of NSW public sector managers. Unpublished report. Independent Commission Against Corruption, New South Wales State Government, Sydney, Australia.

D’Aquila, J. M. (1998). Is the control environment related to financial reporting decisions?. Managerial Auditing Journal, 13, 472-478.

Eisenhardt, K. M. (1989). Agency theory: An assessment and review. Academy of Management Review, 14, 57-74.

Farrell, H., \& Farrell, B. (1997). The Language of Business Codes of Ethics: Implications of Knowledge and Power. Working paper. School of Accounting, University of Technology, Sydney.

Ferrell, O. C., \& Skinner, S. J. (1988). Ethical behavior and bureaucratic structure in marketing research organizations. Journal of Marketing Research, 25, 103-109.

Ford, R. C., \& Richardson, W. D. (1994). Ethical decision making: A review of the empirical literature. Journal of Business Ethics, 13, 205-221.

Gowler, D. \& Legge, K. (1983). The meaning of management and the management of meaning: A view from social anthropology. In Earl, M., Perspectives on Management: A Multidisciplinary Analysis. Oxford: Oxford University Press.

Greenwald, J. (1986). Tylenol decisions to cost Johnson and Johnson about \$150 million. Business Insurance, 20, 2.

Harrell, A., \& Harrison, P. (1994). An incentive to shirk, privately held information, and managers' project evaluation decisions. Accounting, Organizations and Society, 19, 569-577.

Harrison, P., \& Harrell, A. (1993). Impact of 'agency problem' on managers' project evaluation decisions. Academy of Management Journal, 36, 635-643.

Hegarty, W. H., \& Sims, Jr. H. P. (1978). Some determinants of unethical behaviour: An experiment. Journal of Applied Psychology, 63, 451-457.

Hegarty, W. H., \& Sims, Jr. H. P. (19789). Organizational philosophy, policies and objectives related to unethical decision behaviour: A laboratory experiment. Journal of Applied Psychology, 64, 331-338.

Ho, J. L., \& Vera-Muñoz, S. C. (1998). The Effects of loss aversion and attribution on managers' goal-incongruent investment decisions with private information. Accounting, Behavior and Organizations Annual Conference, October, Orlando, Florida.

Independent Commission Against Corruption (1998). Ethics: The key to good management. Sydney: ICAC Report, New South Wales State Government, Sydney, Australia. 
Independent Commission Against Corruption (2000). What is an ethical culture?: Key issues to building an ethical organisation. Sydney: ICAC Report, New South Wales State Government, Sydney, Australia.

Izraeli, D. (1988). Ethical beliefs and behaviour among managers: A cross-cultural perspective. Journal of Business Ethics, 7, 263-271.

Johnson, C. H. (1989). A matter of trust. Management Accountant, 71, 12-13.

Kanodia, C., Bushman, R,. \& Dickhaut, J. (1989). Escalation errors and the sunk cost effect: An explanation based on reputation and information asymmetries. Journal of Accounting Research, 59-77.

Kitson, A., \& Campbell, R. (1996). The ethical organisation. London: MacMillan Press.

Laczniak, G. R., \& Inderrieden, E. J. (1987). The influence of stated organizational concern upon ethical decision making. Journal of Business Ethics, 6, 297-307.

Louwers, T. J., Ponemon, L. A., \& Radtke, R. R. (1997). Examining accountants' ethical behavior: A review and implications for future research. In Arnold, V., \& Sutton, S. G., Behavioral Accounting Research: Foundations and Frontiers. Sarasota, FL: American Accounting Association.

Merchant, K. A. (1989). Rewarding results: Motivating profit centre managers. Boston, Mas.: Harvard Business School Press.

Metzger, M. B., \& Dalton, D. R. (1996). Seeing the elephant: An organizational perspective on corporate moral agency. American Business Law Journal, 33, 489-576.

Miller, A. (1995). Sundae school (Ben \& Jerry’s social responsibility claim). Inc., December 30, 29-30.

Nichols, M. L., \& Day, V. E. (1982). A comparison of moral reasoning of groups and individuals on the "Defining Issues Test". Academy of Management Journal, 25, 201-208.

Noreen, E. (1988). The economics of ethics: A new perspective on agency theory. Accounting, Organizations and Society, 13, 359-369.

Northcraft, G. B., \& Wolf, G. (1984). Dollars, sense and sunk costs: A life cycle model of resource allocation decisions. Academy of Management Review, 9, 225-234.

Passmore, D. J. (1995). Incentives to shirk and private information and ethics in management project evaluation decisions. Bachelor of Business Honours thesis. School of Accounting, University of Technology, Sydney.

Ping, A. C. (1996). An organic perspective on organisational ethics. Management (North Sydney), 17-19.

Ponemon, L. (1992). Auditor underreporting of time and moral reasoning: An experimental lab study. Contemporary Accounting Research, 9, 171-189.

Ponemon, L. (1993). Can ethics be taught in accounting. Journal of Accounting Education, 191-215.

Posner, B. Z. (1986). Individual's moral judgement and its impact on group processes. International Journal of Management, 3, 2, 5-11.

Rich, A. J., Smith, C. S., \& Mihalek, P. H. (1990). Are corporate codes of conduct effective?. Management Accounting, 34-35. 
Rutledge, R. W., \& Karim, K. E. (1999). The influence of self-interest and ethical considerations on managers' evaluation judgments. Accounting, Organizations and Society, 24, 173-184.

Soutar, G., McNeil, M. M., \& Molster, C. (1994). The impact of the work environment on ethical decision making: Some Australian evidence. Journal of Business Ethics, 13, 327-339.

Staw, B. (1976). Knee-deep in the big muddy: A study of escalating commitment to a chosen course of action. Organizational Behavior and Human Performance, 16, 27-44.

Staw, B. M., \& Fox F. V. (1977). Escalation: The determinants of commitment to a chosen course of action. Human Relations, 30, 431-450.

Tsui, J. S. L., \& Gul, F. A. (1996). Auditor's behaviour in an audit conflict situation: A research note on the locus of control and ethical reasoning. Accounting, Organizations and Society, 21, 41-51.

Wiesendanger, B. (1993). Annual report portfolio: Ben \& Jerry scoop up credibility. Public Relations Journal, 49, 20.

Wiley, C. (1995). The ABCs of business ethics: Definitions, philosophies and implementation. Industrial Management, 37, 22-27.

Zey-Ferrell, M. (1979). Predicting unethical behaviour among marketing practitioners. Human Relations, 32, 557-569.

Zucker, L. (1983). Organizations as institutions. Research in the Sociology of Organizations: A Research Annual, 2, 1-47.

Zucker, L. (1987). Institutional theories of organization. Annual Review of Sociology, 13, 443464. 


\section{Endnotes}

1 The general set of agency issues explored in prior papers has been referred to as adverse selection. As they may also be construed as applying to a moral hazard situation, we prefer to use the more general term of agency problems.

2 It should be noted that the majority of research on managers' decision bias in project evaluations have focused on irrational explanations such as a manager's self-justification of prior commitment to a project (Brockner, 1992).

3 This proposition is consistent with the growing body of research on ethics in accounting settings (see Louwers et al., 1997 for a review). For example, Ponemon (1993) found that higher ethical development of students was associated with reduced free-riding behavior in an economic choice experiment and Arnold and Ponemon (1991) found that internal auditors with higher ethical development were more likely to disclose sensitive audit findings even when it was not in their own interests (that is, retaliation by management was likely).

4 Similarly, D’Aquila (1998) argues that research on financial reporting decisions has focused more on individual traits than on a firm's internal control environment, despite the latter's identification as the foundation for all other internal control components.

5 The Independent Commission Against Corruption (ICAC), created by the ICAC Act 1988, is a State public authority, independent of the government of the day, that is accountable to the people of New South Wales (Australia) through the New South Wales Parliament. Its aims are to protect the public interest, prevent breaches of public trust and guide the conduct of public officials (see www.icac.nsw.gov.au).

6 The other two factors are features of the organization (covering scarcity of resources, environmental dynamism, size, prior ethical violations and industry) and corporatization and privatization of public section organizations. Neither of these factors is directly related to the creation and operation of an ethical environment as conceived in this paper.

$7 \quad$ They may also believe that the probability of detection increases due to the possibility of ethical whistle blowing by other managers, but this depends of the nature of opportunistic action they are considering. In our experiments project managers have completely private information on project profitability, so there is no chance of exposure by other managers.

8 Five subjects failed to provide details about their gender.

$9 \quad$ Six subjects failed to provide details about their age.

10 Seven subjects failed to provide details about their work experience.

11 No manipulation was included for the 'Ethics Training' factor as this could not be made directly relevant to the case form of the strong ethical environment manipulation.

12 As for the reported analysis, the ethics main effect $\left(\mathrm{F}_{1,76}=8.305, \mathrm{p}=0.005\right)$ and the agency main effect $\left(\mathrm{F}_{1,76}=5.422, \mathrm{p}=0.023\right)$ were significant and the interaction was not significant.

13 The statistical package SYSTAT 10 controls for unbalanced data sets by conducting an unweighted means analysis. 